\title{
Massive hemothorax caused by Gelpi retractor during posterior correction surgery for adolescent idiopathic scoliosis: a case report
}

\author{
Long Pang ${ }^{1}$, Kota Watanabe ${ }^{2}$, Yoshiaki Toyama ${ }^{1}$ and Morio Matsumoto ${ }^{1 *}$
}

\begin{abstract}
Background context: Gelpi retractors are used in surgery because they can reduce paravertebral muscle damage during retraction. No pleural injuries associated with their use in posterior spine surgery have been reported.

Purpose: To describe a patient who suffered a massive postoperative hemothorax caused by a Gelpi retractor used during posterior correction surgery for adolescent idiopathic scoliosis (AIS).

Study design: Case report.

Methods: A case report of a rare hemothorax complication due to a Gelpi retractor is reported. The relevant literature was reviewed.

Results: A 12-year-old girl with Lenke type 2 AIS, with curves of $60^{\circ}$ at $\mathrm{T} 2-7$ and $75^{\circ}$ at $\mathrm{T} 7$ - L1, underwent posterior correction and fusion surgery using a segmental pedicle screw construct placed between T2 and L2. Although the patient's vital signs were stable during and soon after the surgery, a chest $\mathrm{x}$-ray taken one day later revealed a massive left hemothorax. Her hemoglobin concentration was decreased to $5.5 \mathrm{~g} / \mathrm{dl}$, and $\mathrm{SpO}_{2}$ remained as low as $92 \%$ even with oxygen administration. Thoracoscopy revealed subpleural hemorrhaging at several points in the left upper intercostal area (T3-6), and a penetration of the pleura between the left 4th and 5th ribs. Active bleeding had already stopped. The tip of the Gelpi retractor appeared to have penetrated the pleura. A chest tube was placed in the patient to treat the hemothorax.

Conclusions: A pleural injury by the Gelpi retractor was determined to be the cause of the hemothorax in this case. The patient's prominent thoracic hump may have increased the risk of such an injury because the tip of a Gelpi retractor might easily have become stuck in the intercostal space rather than the paravertebral muscles.
\end{abstract}

\section{Background}

Current advancements in surgical technique, spinal implants, and monitoring systems for vital organs are conducive to safe and favorable outcomes in posterior correction and fusion surgery for adolescent idiopathic scoliosis (AIS). Nonetheless, intra- and postoperative complication rates are reported to be $11.5 \%$ and $0.86 \%$ for non-neurologic and neurologic adverse events, respectively, in patients who underwent surgery $[1,2]$. Of these, the reported complication rate for postoperative hemothorax is as low as $0.1 \%$ [3-5], usually associated

\footnotetext{
*Correspondence: morio@a5.keio.jp

'Department of Orthopedic Surgery, Keio University, 35 Shinanomachi,

Shinjuku, Tokyo 160-8582, Japan

Full list of author information is available at the end of the article
}

with thoracoplasty or misplaced pedicle screws [6,7]. Here, we describe an AIS patient who developed a hemothorax as a consequence of a pleural injury incurred by the Gelpi retractor used during surgery (Figure 1).

\section{Case presentation}

History and physical examination

A 12-year-old girl with AIS was referred to our department for surgical treatment due to progression of the curve. Physical examination revealed a prominent rib hump on the right side, and slight elevation of the left shoulder. Her body weight was $32.7 \mathrm{~kg}(-1.53 \mathrm{SD})$ and height was $144.0 \mathrm{~cm}$ (-1.54D). Radiographs showed scoliosis of $65^{\circ}$ at T2-7 and $75^{\circ}$ at T7-L1, and kyphosis of $60.8^{\circ}$ at T5-12 (Figure 2). Supine side-bending 


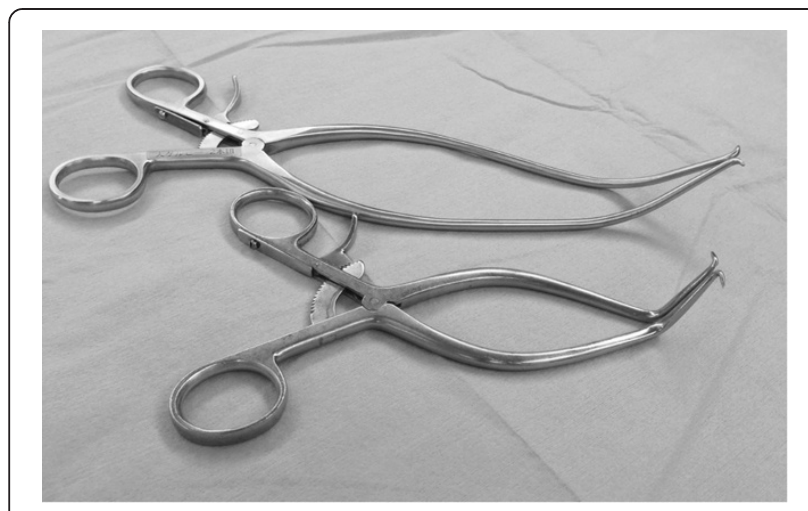

Figure $1 \mathrm{Gelpi}$ retractor. The Gelpi retractor is a self-retaining retractor, which has two blades that are hinged at the middle.

radiographs revealed scoliosis of $51.4^{\circ}$ at $\mathrm{T} 2-7$ and $62.1^{\circ}$ at T7-12, with curve flexibilities of $20.5 \%$ and $17.4 \%$, respectively. The Lenke classification was type $2 \mathrm{~A}+$. Threedimensional computed tomography (CT) images showed no congenital deformity of the thoracic or lumbar spine. Pulmonary function tests revealed a slight decrease in vital capacity (74\%) and a normal forced expiratory volume in one second (86.3\%).

\section{Surgery}

The patient underwent posterior correction and fusion surgery with a pedicle screw construct between T2 and L2. After the posterior elements of the thoracic spine were exposed, pedicle screws were placed bilaterally using the ball-tip probe technique [8]. No obvious pedicle perforation was noted during screw placement. Ponte osteotomies were added at T3/4, 4/5, T7/8, 8/9, 9/ 10 to increase flexibility of the thoracic curves. The curves were corrected by placing a rod on the concave side of the main thoracic curve followed by a rod rotation maneuver and in-situ contouring. The scoliosis was corrected to $19^{\circ}$ and $15^{\circ}$, respectively, with correction rates of $71 \%$ and $80 \%$.

Postoperatively, the patient's hemodynamics were stable and the saturation of pulse oximetory $\left(\mathrm{SpO}_{2}\right)$ was kept at $100 \%$. Blood hemoglobin level was $8.1 \mathrm{mg} / \mathrm{dl}$, and blood red cell count was $4.49 \times 10^{6} / \mu \mathrm{l}$. However, 18 hours later, her hemoglobin concentration had decreased to $5.5 \mathrm{~g} / \mathrm{dl}$

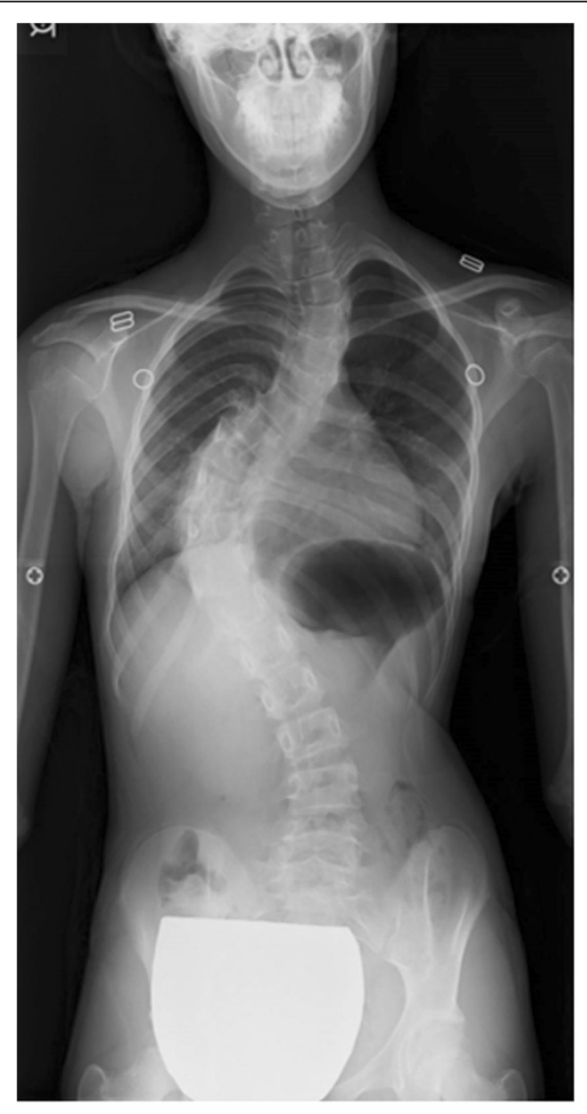

a

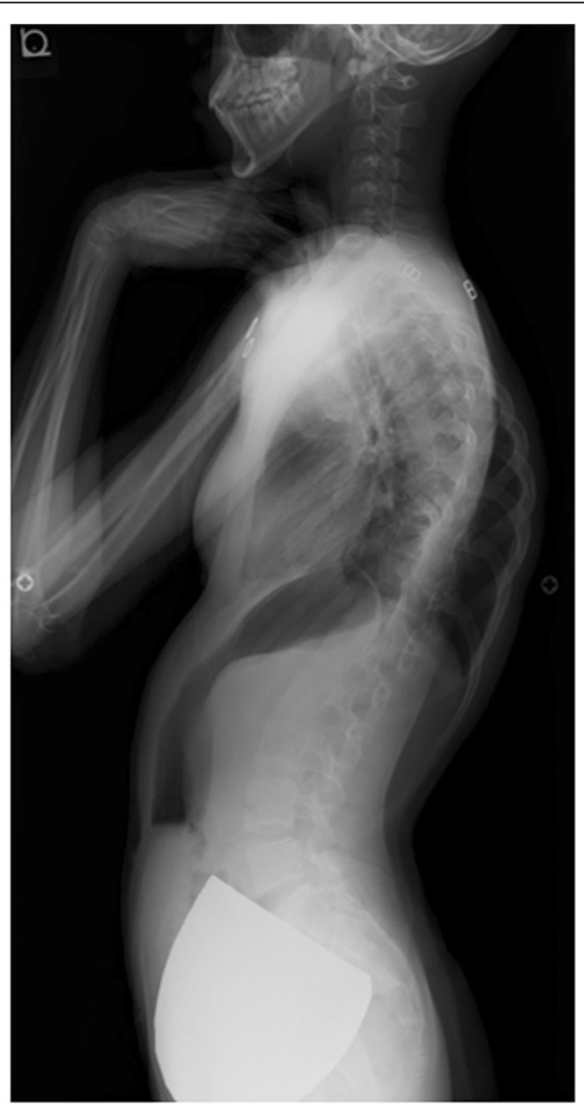

b

Figure 2 Standing whole spine radiographs. Standing radiographs show scoliosis of $65^{\circ}$ at $\mathrm{T} 2-7$ and $75^{\circ}$ at $\mathrm{T} 7-12$ (a), and kyphosis of $61^{\circ}$ at T5-12 (b). 
and red cell count had fallen. $\mathrm{SpO}_{2}$ was $92-100 \%$ even with oxygen administration. A chest X-ray taken at that time showed a massive opacification in the left thorax (Figure 3), and a contrasted chest $\mathrm{CT}$ revealed a massive hemothorax on the left side. However, the CT images showed neither definitive arterial bleeding nor misplaced pedicle screws. To determine the cause of the hemothorax and treat the bleeding, thoracoscopy was performed. This analysis revealed several subpleural hemorrhages in the left T3 and T4 intercostal areas (Figure 4) and a penetration of the pleura between the left 4th and 5th intercostal areas from which active bleeding had already stopped. These complications were consistent with injuries caused by the tip of the Gelpi retractor used to expose the surgical field during surgery. A chest tube was placed to treat the hemothorax, and removed after twelve hours. The patient was discharged 10 days later without any respiratory problems.

\section{Discussion}

The overall prevalence of non-neurologic complications associated with the surgical management of AIS ranges from $0 \%$ to $15.4 \%$ [9-13]. A study of complications after surgery on 702 AIS patients found an overall prevalence of $15.4 \%$, with ten respiratory complications [1]. Factors including age, pulmonary function, surgical approach,

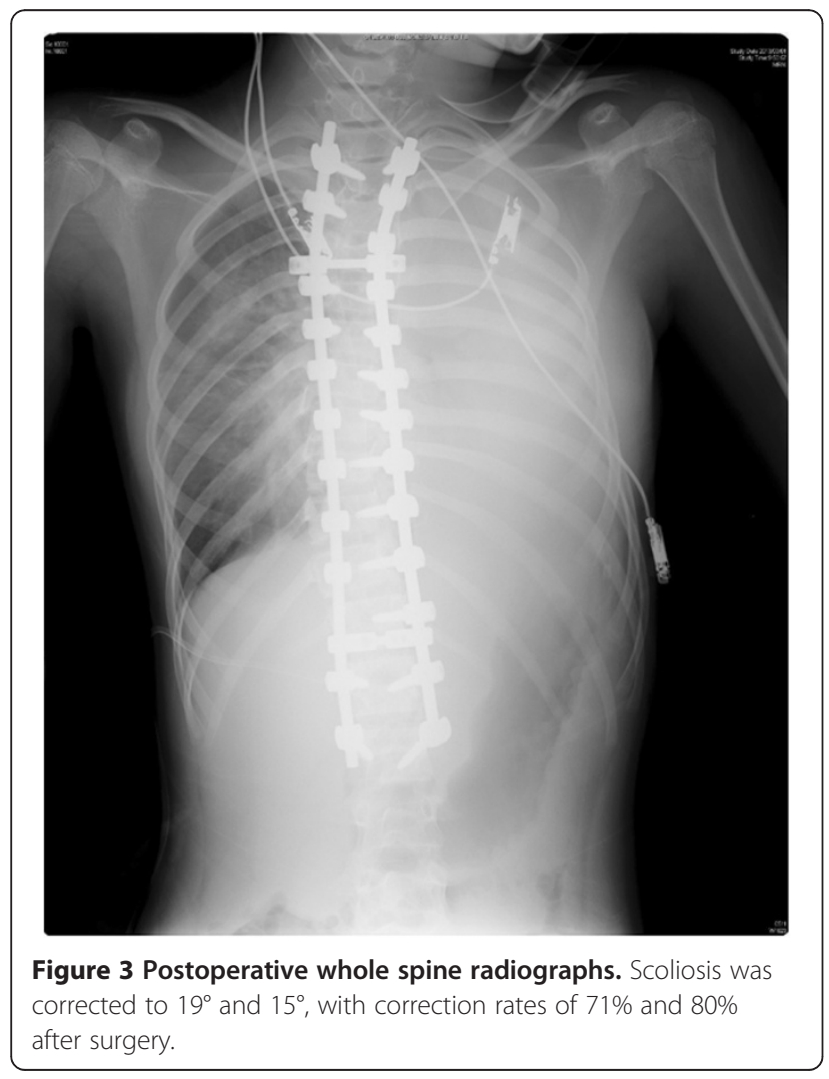

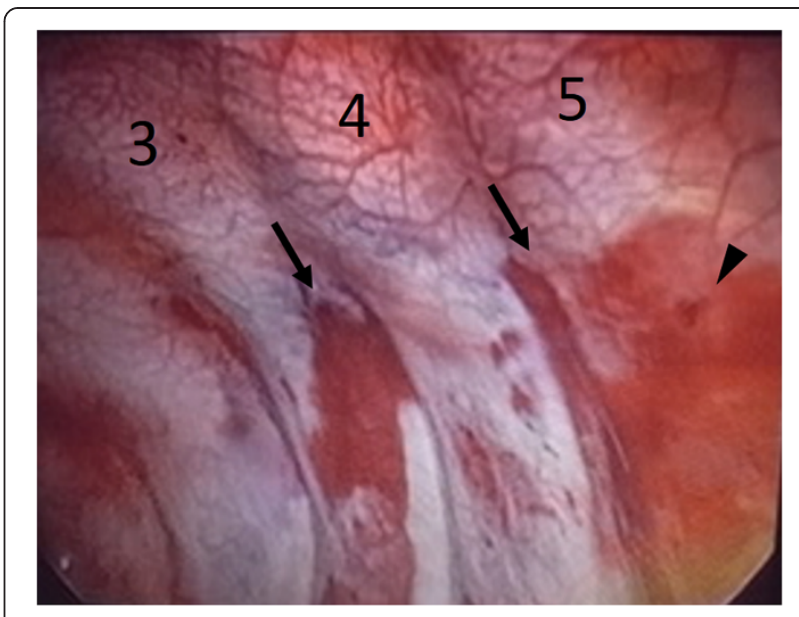

Figure 4 Postoperative chest radiograph. A chest radiograph taken 18 hours after surgery shows a massive hemothorax in the left lung. number of levels fused, Lenke curve type, or region of the major curve did not correlate with an increased complication rate.

Among the perioperative complications seen in posterior correction and fusion surgery for AIS, hemothorax is quite rare, and usually associated with thoracoplasty or misplaced pedicle screws [4,14]. Systematic reviews of 1666 and 5654 AIS patient records each identified only one instance of hemothorax following posterior surgery $[3,4]$. These cases originated from thoracoplasty or misplaced pedicle screws. A rongeuer used to perform the Ponte osteotomies may also have caused some vascular damage.

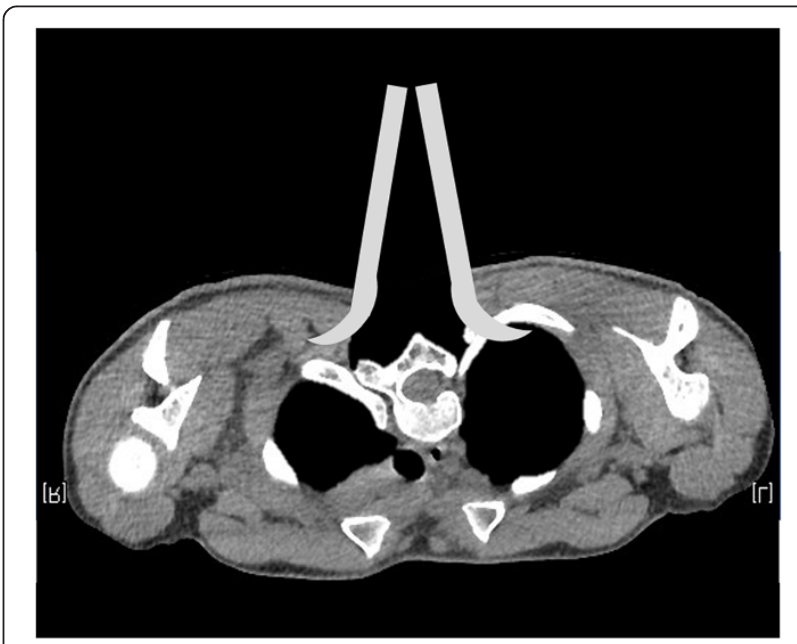

Figure 5 Thoracoscopy findings. Thoracoscopy shows subpleural hemorrhages at the left T3 and 4 ribs, and penetration of the pleura between the left 4 th and 5 th ribs. 
The pointed tips of the blades in a Gelpi retractor push the edges of the wound apart, and retain themselves in it, easing exposure of the surgical field and reducing the intraoperative damage to paravertebral muscles during retraction (Figure 1). However, in the present case, a prominent rib hump on the left side of the upper thoracic area may have increased the risk of pleural injury by the retractor tip (Figure 5). To our knowledge, this is the first report describing a postoperative hemothorax caused by a Gelpi retractor. Surgeons should be aware of this complication when using a retractor with relatively sharp tips, especially in thoracic spine with deeper wound retraction.

\section{Conclusions}

A 12-year-old female with adolescent idiopathic scoliosis underwent posterior correction and fusion surgery using pedicle screws. Postoperatively, her pleura was revealed to have been penetrated, with some subpleural hemorrhaging. The injury was caused by the tips of a Gelpi retractor used to reduce paravertebral muscle injury during retraction.

\section{Consent}

Written informed consent was obtained from the parents of the patient for publication of this case report and any accompanying images. A copy of the written consent is available for review from the Editor-in-Chief of this journal.

\section{Competing interests}

The authors declare that they have no competing interests.

\section{Authors' contributions}

LP and KW conceived the study and drafted the manuscript; MM and KW performed surgeries, and performed critical revision of the manuscript; $Y T$ gave final approval of the version to be published. All authors read and approved the final manuscript.

\section{Author details}

'Department of Orthopedic Surgery, Keio University, 35 Shinanomachi, Shinjuku, Tokyo 160-8582, Japan. ${ }^{2}$ Department of Advanced Therapy for Spine and Spinal Cord Disorders, Keio University, Tokyo, Japan.

Received: 10 August 2014 Accepted: 19 October 2014

Published: 25 October 2014

\section{References}

1. Carreon LY, Puno RM, Lenke LG, Richards BS, Sucato DJ, Emans JB, Erickson MA Non-neurologic complications following surgery for adolescent idiopathic scoliosis. J Bone Joint Surg Am 2007, 89(11):2427-2432.

2. Diab M, Smith AR, Kuklo TR: Neural complications in the surgical treatment of adolescent idiopathic scoliosis. Spine (Phila Pa 1976) 2007, 32(24):2759-2763

3. Gautschi OP, Schatlo B, Schaller K, Tessitore E: Clinically relevant complications related to pedicle screw placement in thoracolumbar surgery and their management: a literature review of 35,630 pedicle screws. Neurosurg Focus 2011, 31(4):E8.

4. Hicks JM, Singla A, Shen FH, Arlet V: Complications of pedicle screw fixation in scoliosis surgery: a systematic review. Spine (Phila Pa 1976) 2010, 35(11):E465-E470.
5. Levine DS, Dugas JR, Tarantino SJ, Boachie-Adjei O: Chance fracture after pedicle screw fixation: a case report. Spine (Phila Pa 1976) 1998, 23(3):382-385. discussion 6.

6. Modi HN, Suh SW, Hong JY, Cho JW, Park JH, Yang JH: Treatment and complications in flaccid neuromuscular scoliosis (Duchenne muscular dystrophy and spinal muscular atrophy) with posterior-only pedicle screw instrumentation. Eur Spine J 2010, 19(3):384-393.

7. Shapiro G, Green DW, Fatica NS, Boachie-Adjei O: Medical complications in scoliosis surgery. Curr Opin Pediatr 2001, 13(1):36-41.

8. Watanabe K, Matsumoto M, Tsuji T, Ishii K, Takaishi H, Nakamura M, Toyama Y, Chiba K: Ball tip technique for thoracic pedicle screw placement in patients with adolescent idiopathic scoliosis. J Neurosurg Spine 2010, 13(2):246-252.

9. Bago J, Ramirez M, Pellise F, Villanueva C: Survivorship analysis of CotrelDubousset instrumentation in idiopathic scoliosis. Eur Spine J 2003, 12(4):435-439.

10. Richards BS, Herring JA, Johnston CE, Birch JG, Roach JW: Treatment of adolescent idiopathic scoliosis using Texas Scottish Rite Hospital instrumentation. Spine (Phila Pa 1976) 1994, 19(14):1598-1605.

11. Danielsson AJ, Nachemson AL: Radiologic findings and curve progression 22 years after treatment for adolescent idiopathic scoliosis: comparison of brace and surgical treatment with matching control group of straight individuals. Spine (Phila Pa 1976) 2001, 26(5):516-525.

12. Dickson $\mathrm{JH}$, Erwin WD, Rossi D: Harrington instrumentation and arthrodesis for idiopathic scoliosis: a twenty-one-year follow-up. J Bone Joint Surg Am 1990, 72(5):678-683.

13. Luhmann SJ, Lenke LG, Bridwell KH, Schootman M: Revision surgery after primary spine fusion for idiopathic scoliosis. Spine (Phila Pa 1976) 2009, 34(20):2191-2197.

14. Ogura Y, Watanabe K, Hosogane N, Toyama Y, Matsumoto M: Acute respiratory failure due to hemothorax after posterior correction surgery for adolescent idiopathic scoliosis: a case report. BMC Musculoskelet Disord 2013, 14:132

\section{doi:10.1186/1748-7161-9-17}

Cite this article as: Pang et al:: Massive hemothorax caused by Gelpi retractor during posterior correction surgery for adolescent idiopathic scoliosis: a case report. Scoliosis 2014 9:17.

\section{Submit your next manuscript to BioMed Central and take full advantage of:}

- Convenient online submission

- Thorough peer review

- No space constraints or color figure charges

- Immediate publication on acceptance

- Inclusion in PubMed, CAS, Scopus and Google Scholar

- Research which is freely available for redistribution 